\title{
Criterios \\ Patrimonio y paisaje. Proyecto en el litoral malagueño
}

Esther López Martín

Arquitecta. Instituto Andaluz del Patrimonio Histórico

\section{Resumen}

Los paisajes contemporáneos están sometidos a cambios profundos y rápidos que los convierten en irreconocibles en un corto espacio de tiempo. El ser humano corre el riesgo de desvincularse de su entorno. Sin embargo, el estudio sobre el patrimonio en el paisaje puede salvar esta situación. Se ha realizado una aplicación práctica en el litoral malagueño, claro ejemplo de transformación acelerada debido a la expansión del turismo y la agricultura bajo invernadero en la zona.

\section{Palabras clave}

\section{Arquitectura}

Internacional Situacionista

Málaga

Ordenación del territorio

Paisaje cultural

Patrimonio cultural

Proyecto de Paisaje

Teoría de la Deriva
Los conceptos de Patrimonio y Paisaje hasta hoy se han analizado por separado, pero la realidad los evidencia cada día más vinculados entre sí. El patrimonio se ha convertido en los últimos años en una disciplina consolidada en la sociedad como parte fundamental del proceso urbano y arquitectónico, un hecho que interviene en cómo se planifica una ciudad, cómo se rehabilita un edificio, etc. Sin embargo, el estudio del paisaje es bien diferente, supone una disciplina emergente, y aún no existe la consciencia social de la necesidad de su conservación, protección, restauración, documentación y profundo conocimiento. A pesar de lo anterior, de los diferentes tratamientos y grados de evolución que le damos al patrimonio y al paisaje, la realidad contemporánea nos va revelando que no sólo es fundamental el estudio del paisaje desde nuestro presente, sino que va unido intrínsecamente al hecho patrimonial.

Si observamos nuestro entorno, veremos que se ha transformando con rapidez, de una forma descontrolada y casi intuitiva, donde abundan los lugares sin una planificación previa y los crecimientos urbanos ilegales y sin ordenar. Los límites de la ciudad se han ido difuminando. Antes, el esquema del territorio se estructuraba en zonas claramente urbanas y otras claramente rurales, había importantes diferencias entre el campo y la ciudad. Hoy, esta circunstancia ha cambiado notablemente, afloran las segundas residencias diseminadas en el territorio no urbano y las explotaciones agrícolas e industriales en ámbitos rurales. Lo que antes era no urbano, donde la ciudad dejaba de ser ciudad, hoy tiene una presencia permanente de invasión de nuevas formas económicas, consecuencia de los procesos de producción actuales: centros comerciales, segundas residencias, agricultura bajo plástico. Este nuevo paisaje descontrolado, dada su extensión en el territorio, hoy se plantea como un problema a estudiar principalmente desde el binomio paisaje-patrimonio.

La secuencia de las cuatro estaciones tan características del paisaje agrícola tradicional se ha transformado en las nuevas periferias, generando un espacio en el que la presencia de lo natural se entremezcla con lo artificial. Esto que podría parecer algo específico y exclusivo de las periferias de las grandes ciudades, también se produce, y con mayor ferocidad, en los entornos de los espacios con alto valor natural (parques naturales y litoral) y en las pequeñas ciudades: las nuevas agriculturas y las segundas residencias han ido colonizando el territorio periférico. Por todo lo anterior, se entiende que estas periferias que en principio parecían generadas por la gran ciudad, en realidad son una forma de crecimiento de nuestro presente, algo generalizado en el territorio y que conviene tratar desde una acción contemporánea, ya que los modelos tradicionales urbanísticos no pueden controlar esta forma mutante de crecimiento. Se ha observado que los modernos modelos urbanísticos de ciudad acabada y zonificada con los que se ha trabajado tradicionalmente en el siglo XX son ineficaces ante esta problemática por ser poco flexibles ante los nuevos agentes y la forma de crecer real de la ciudad. Por lo anterior, surge la necesidad de una nueva forma de actuación. 


\section{Criterios}

Patrimonio y paisaje. Proyecto en el litoral malagueño

\section{Lógica contemporánea}

Los paisajes se encuentran repletos de hechos simultáneos que se cruzan en el espacio, de Historia y de acontecimientos, también de graves errores; en general se podría decir que en un paisaje coexisten multitud de capas de información, cada una de ellas específica y diferente de todas las demás. Este hecho donde se acumulan los datos y las posibles lecturas del territorio nos desvela la complejidad del mismo.

La problemática al enfrentarse al exceso de información ya existía anteriormente, los paisajes ya tenían multitud de circunstancias que acontecían a un mismo tiempo, aunque la lectura que se hacía de los mismos carecía de complejidad. Tradicionalmente el concepto de paisaje se ha encontrado unido a una visión contemplativa y en parte idealista, procedente en muchas ocasiones de las antiguas expresiones pictóricas (el paisajismo). Mirar un paisaje era como deleitarse ante un cuadro paisajista, donde mediante la simplificación de un conjunto se llegaba a una imagen única y representativa de la totalidad. Sin embargo, en los últimos tiempos la mirada hacia el paisaje se ha ido transformando en un acontecimiento donde el análisis se realiza por descomposición de cada uno de los agentes participantes que lo componen para una posterior superposición de datos. Esta posibilidad incorpora múltiples visiones de un mismo paisaje variando éstas en función de qué agentes son los que se han seleccionado para la representación y de cómo los hemos combinado.

Uno de los pioneros en el estudio del paisaje tal y como lo empezamos a entender en la actualidad fue lan $\mathrm{McHarg}^{1}$, quien desarrolló un método gráfico mediante el cual, dada la planimetría de un sector, iba dibujando en mapas diferentes (en papel translúcido) las circunstancias que son importantes para tomar una decisión urbanística 0 medioambiental, manchando cada plano, de manera que al superponer todos los planos de papel translúcido, había áreas que quedaban sin manchar y otras en las que se superponían unas manchas encima de otras. Del resultado se extraían conclusiones sobre las áreas en blanco (sin manchas), ya que éstas no cumplían ningún requerimiento de los que se le había impuesto, al igual que sobre las manchadas, donde coincidían uno o varios condicionantes a la vez. A este método se le llamó "Método de exclusión de McHarg". Lo simple del método implicaba una complejidad importante: la superposición de información. Este hecho era imposible con la tradicional zonificación urbanística, donde a cada sector corresponde un solo uso. Hoy, esta superposición se estudia como un hecho real e inevitable y se asume la complejidad de la misma.

Otro de los conceptos avanzados por lan McHarg es la nueva relación del hombre con el medio. Desarrolló una investigación donde la protección de lo natural es la base del proyecto, siendo este hecho uno de los primeros momentos en los que el patrimonio natural se concibe como sustrato del paisaje. Es decir, ya en 1969, cuando se publica su libro "Proyectar con la Naturaleza", avanzaba la protección del medio natural como base para el desarrollo del territorio.
Conforme a la forma de trabajo expresada con anterioridad y gracias a los medios actuales de que disponemos, entender un territorio nos permite asumir toda la complejidad que lo compone. La posibilidad que nos ofrecen las nuevas tecnologías nos permite alternar y superponer multitud de capas de información. Hoy obtener información geográfica no supone un problema en la mayor parte del territorio, incluso podemos alternar las capas según las combinaciones que nos interesen. La mirada desde lo geográfico, económico, paisajístico, patrimonial, cultural, físico, histórico..., superpuesta en el territorio, es en la actualidad posible. No obstante, debido al exceso y fácil accesibilidad a la información, se convierte en crucial la toma de decisiones respecto a qué información incorporamos a nuestro proyecto y qué capas podemos combinar para el desarrollo del mismo.

La superposición de la información nos aporta además un nuevo concepto: la posibilidad de combinar capas para conseguir nuevas lecturas. Esto que en principio parece algo muy sistemático, también permite un juego de combinatorias azaroso en busca de esa nueva definición. Podemos por tanto utilizar las superposiciones buscando nuevas lecturas del territorio y esto además nos permitiría cambiar el soporte de trabajo consiguiendo nuevos resultados en la intervención.

\section{El tiempo}

La posibilidad de tener distintas informaciones de un mismo lugar nos permite incorporar el factor tiempo al planeamiento, ya que el paisaje de un lugar cambia en función de en qué momento es observado, tal y como vemos en los ejemplos siguientes: las visitas fuera de temporada a núcleos turísticos 0 en horario no laboral a zonas de oficinas, 0 en periodo no lectivo a zonas de estudiantes, hace que descubramos que el planeamiento siempre se ha pensado como algo definitivo y concluyente, y la realidad es que el territorio se comporta de una forma más viva, cambia cada año, cada mes o cada hora según el caso ${ }^{2}$. Cuando proyectamos un espacio urbano, deberíamos pensarlo no con una función sino con muchas de ellas, podríamos pensar un edificio universitario para cuando los estudiantes se encuentran de vacaciones 0 un teatro para los momentos en los que no hay actuación. El territorio debería pensarse por tanto, en el transcurrir del tiempo, ya que esto lo acercaría en gran medida a la realidad. Por ejemplo, para suavizar el paisaje de plástico que se produce en las zonas agrícolas bajo invernadero y que muchas veces ocupa grandes extensiones territoriales, se podrían realizar planos de alternancia en el tiempo de tipos de cultivo para, además de oxigenar el suelo, tener una importante mejora paisajística, de manera que existiera la posibilidad de cada año hacer un cultivo diferente; el paisaje pasaría de plástico a verde, marrón, nuevamente plástico.... según la época del año. Igualmente en zonas no agrícolas sino turísticas, se podrían representar los planos de ocupación y usos del turismo cada mes del año, para hacer propuestas de posibles transformaciones en las que un mismo lugar se use en verano de una forma y en invierno de otra. De esta manera podríamos ver cómo se mueve la población 
1. Instalación Paisajística de equipo West8 en Charleston (USA). Fuente: Amidon, Jane. Paisajes Radicales. Barcelona: Blume, 2003

2. Cultivo bajo plástico en Almería

3. Paisaje. Complejidad urbana

de zonas turísticas en invierno, estudiar las necesidades y equipamientos que tienen y hacerlos compatibles con el turismo de verano.

\section{Mutaciones $^{3}$}

Las nuevas formas de producción y la incorporación del ocio a la vida cotidiana generan todo un engranaje de crecimiento de lo construido que discurre aceleradamente en el tiempo. Se le llama mutación, debido al inmenso cambio que se produce en tan corto espacio de tiempo y a que es un proceso vivo y en evolución continua. Lo que antes necesitaba años para consolidarse, hoy se construye, usa y consolida en meses. Este proceso, acelerado en el tiempo, da la voz de alerta para reflexionar, antes de intervenir en un lugar, respecto a si estamos haciendo desaparecer su identidad o no. Debemos para ello incorporar necesariamente al proceso a todos los agentes que intervienen en el territorio. Actualmente, las transformaciones teritoriales son tan espectaculares que pueden hacer irreconocible un lugar después de su mutación en un corto espacio de tiempo. El estudio del patrimonio en estas circunstancias se convierte en un hecho decisivo e imprescindible que debe encontrarse incorporado al proyecto de gran escala necesariamente, como parte importante del pensamiento sobre el paisaje. Bajo esta premisa las intervenciones deberían ser sensibles a los aspectos territoriales identificativos del lugar, encontrando así una nueva forma de crear paisaje.

\section{Naturaleza y artificios del paisaje}

Si entendemos que el paisaje lo constituyen las construcciones naturales y artificiales presentes en nuestro entorno, tendríamos una lectura simple y concreta con la que se puede trabajar en algunas áreas, por ejemplo, todas aquéllas donde lo natural y lo artificial se encuentren diferenciados plenamente, por ejemplo en los Parques Naturales. Esta circunstancia permite que se actúe dentro de estos espacios naturales mediante un proyecto paisajístico de dos formas bien diferenciadas ${ }^{4}$; ambas buscan descubrir el paisaje, sin embargo, las formas de proceder son muy diferentes. La primera trabaja muy vinculada a la materialidad natural del lugar en el que actúa, y la segunda juega a incorporar lo menos natural y más artificioso al paisaje.

Dentro del primer grupo podríamos arrancar con el concepto que utiliza el Land $A r c{ }^{5}$ respecto al paisaje, no como escenario sino como instrumento de proyecto, y la lectura de la naturaleza como algo mestizo y salvaje. Esta forma de proceder se acerca mucho a nuestra realidad por trabajar con los materiales naturales que tradicionalmente nos resultan conocidos: la arquitectura que quiere ser naturaleza, las cubiertas de grandes edificios que son espacios públicos verdes, los pabellones y rascacielos con revestimientos de camuflaje. La huida de la imagen bucólica del paisaje supone una vuelta a la realidad que nos ayuda a entender los lugares desde su complejidad y ver que los crecimientos artificiales también son paisaje, por lo tanto pueden ser estudiados, planificados, restaurados... y estructurados en el territorio.

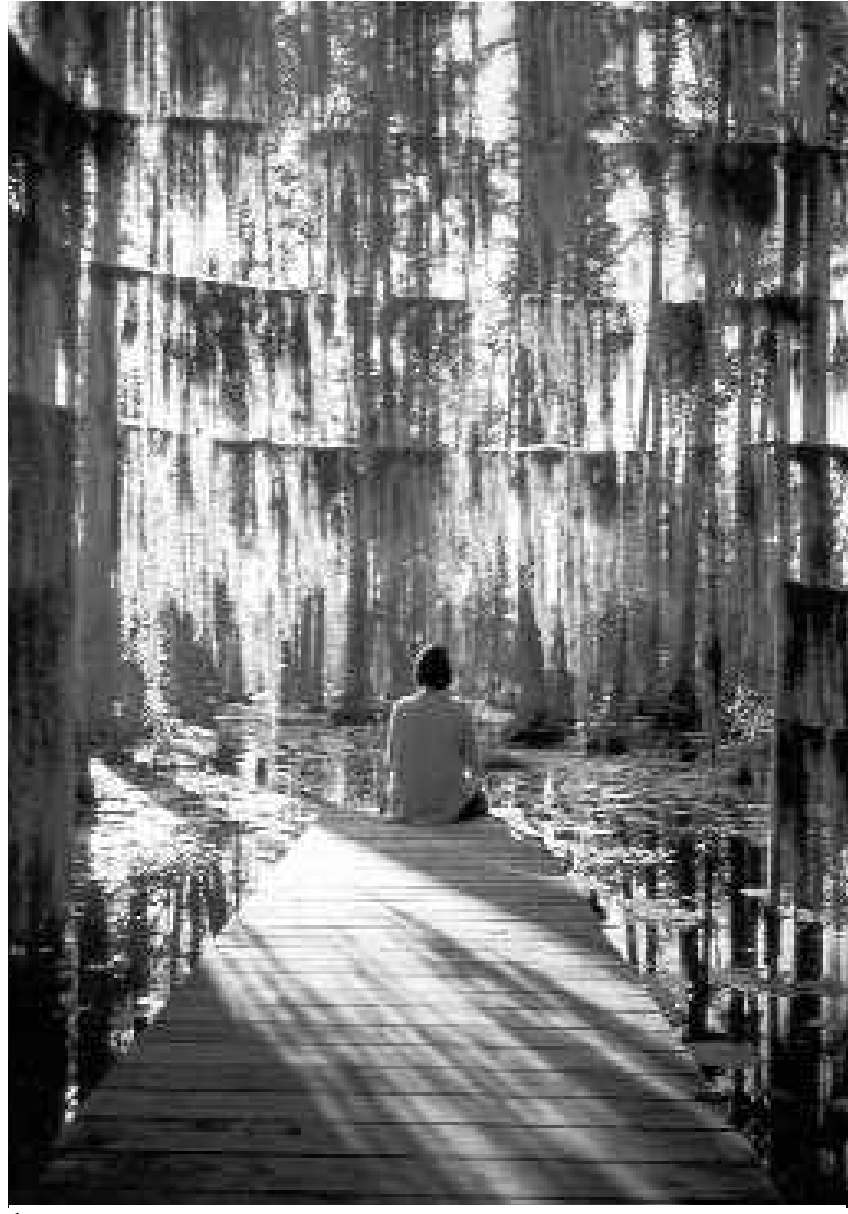

1

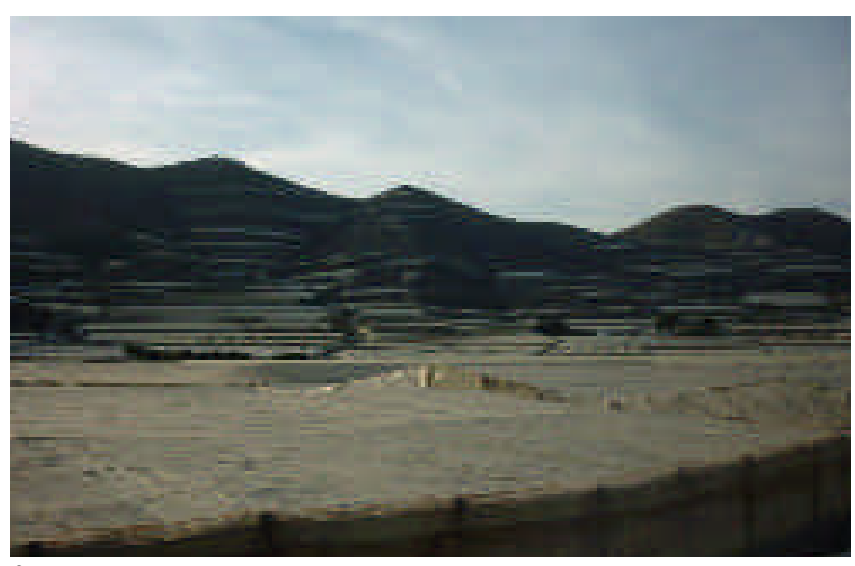

2

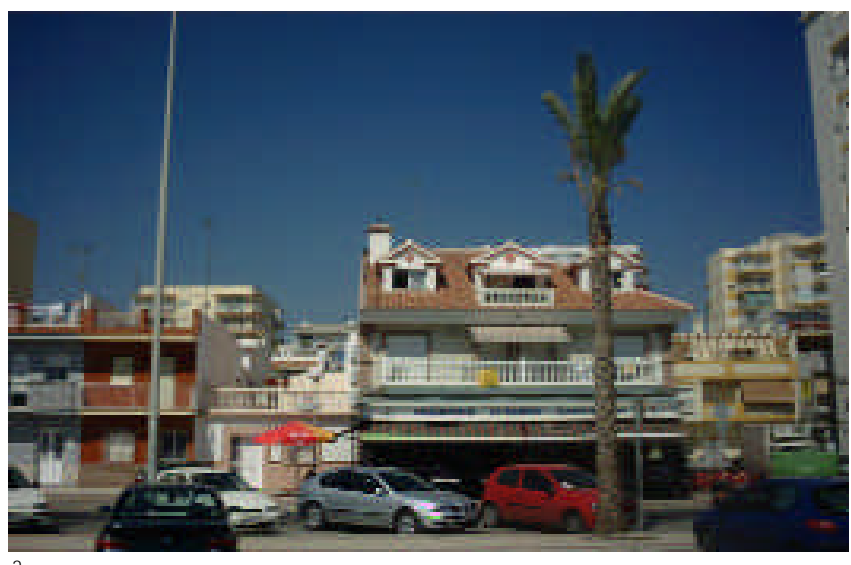

3 


\section{Criterios}

Patrimonio y paisaje.

Proyecto en el litoral

malagueño

Esther López Martín

Esta mirada enriquece enormemente la lectura del territorio, ya que no nos presenta lo artificial como algo que se inserta en un medio natural, sino como un germen que se desarrolla en él, permitiendo proyectar casi como haría un cirujano, cosiendo, curando, reestructurando y reciclando el territorio ${ }^{6}$ (imagen 1 ).

En el segundo grupo, se parte de la base de que lo natural se entiende como un fondo inabarcable desde lo arquitectónico como instrumento de proyecto y donde el proyectista coloca elementos artificiales que ponen en valor ese espacio natural ${ }^{7}$. Insertaríamos un objeto abstracto en el paisaje que conseguiría, diferenciando muy claramente arquitectura (artificio) de paisaje (natural), enseñar a ver desde el presente al espectador el paisaje que se arroja como una realidad expectante. En este caso la arquitectura no quiere ser naturaleza, asume su absoluta diferenciación respecto a su entorno. Su función en el paisaje es la de extraer su belleza y mostrársela al visitante

Ambas opciones son perfectamente válidas cuando nos enfrentamos a un paisaje donde el hombre ha intervenido poco, donde podemos hablar de lo natural como una realidad, donde la naturaleza se encuentra presente.

Lo complejo y muy novedoso se incorpora a este proceso cuando el paisaje que estudiamos no tiene esas características de paisaje natural, por encontrarse ya muy antropizado y donde ninguno de los dos modelos de actuación nos resulta válido. En estos lugares, lo natural es casi inexistente, y es el hombre el que ha hecho mutar al territorio. Tenemos mucho paisaje de estas características extendido a lo largo de todo nuestro entorno: grandes núcleos industriales, litoral turístico y la agricultura bajo invernadero. Es entonces cuando vemos una posible forma de trabajo que resuelva esta problemática: descubrir lo intrínseco del paisaje, lo que le da una identidad.

\section{Desde el interior del territorio: el Patrimonio}

Cada paisaje es diferente e identificativo de un lugar; a pesar de la homogenización que se produce entre muchas ciudades, sobre todo en el ámbito urbano, y el desarraigo que este hecho conlleva, el ser humano necesita poder identificar su territorio y diferenciarlo de los otros. Por ello, al actuar en el paisaje, encontrar las huellas del patrimonio se convierte en clave fundamental para su ordenación. Aquí encontramos un vínculo entre paisaje y patrimonio, que hace que nuestro paisaje sea nuestro patrimonio, y que se convierta en un sustrato de proyecto, en las huellas de nuestra identidad.

Algo que parece tan simple, se dificulta enormemente cuando son multitud de circunstancias las que participan en el proceso.

En su artículo "La vida entre dos paisajes", el escritor Vicente Verdú escribía sobre Shangai, uno de los lugares más desarrollados reciente-

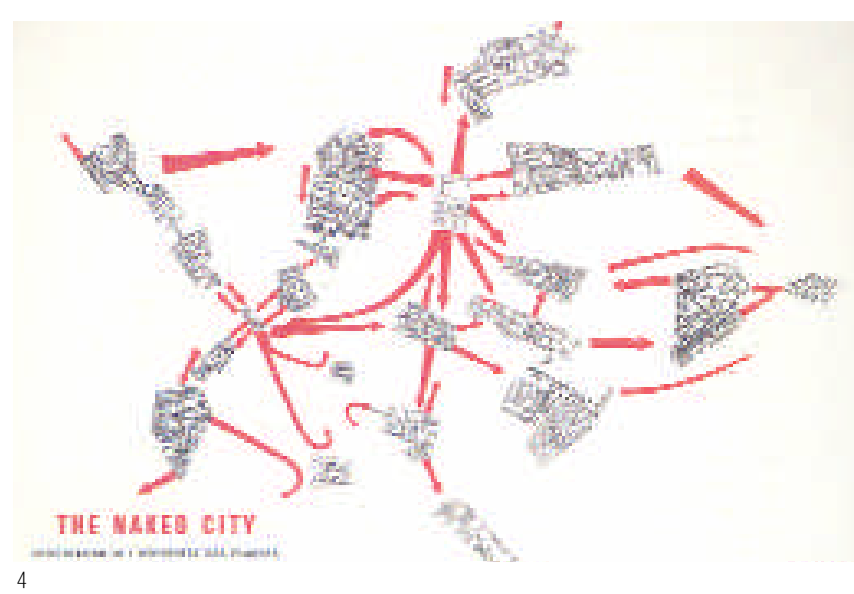

mente, y comentaba que los edificios de esta ciudad "no eran nada chinos", más bien un calco de ciudades norteamericanas como Denver 0 Phoenix, convirtiéndose en no lugares, o lugares sin identidad ${ }^{8}$

Dentro del estudio patrimonio-paisaje cabe mencionar el binomio patrimonio-ecología ya que con él se puede concretar la puesta en valor de lo identificativo y utilizado de un lugar, con objeto de mejorar el disfrute del territorio. El estudio exhaustivo e interdisciplinar de la ecología, sienta las bases para abordar algunos aspectos del patrimonio del paisaje, siendo parte importante y generadora de equilibrio de una correcta intervención.

Hemos hablado de lo identificativo de un paisaje, de formas diferentes de mirar, de patrimonio y de ecología. Todo ello contribuye a plantear una forma de acercamiento a un entorno, pero el estudio debe ser además muy flexible y abierto. En la planificación, se deben dejar lugares libres donde el ciudadano proponga un uso: solares vacíos. Espacios donde a nivel exclusivamente local se organicen acciones vecinales, donde la participación ciudadana sea fundamental. Estos lugares aún sin inventar están concebidos con una clara temporalidad casi instantánea. Es un apunte para un proyecto inacabado, libre y multifuncional, un territorio donde se dejen espacios sin planificar, ya que, dado que tienen una estrategia que los estructura en el territorio, no necesitan zonificarse pormenorizadamente.

\section{Intervención y estructuración del Territorio}

Antes de la existencia de los Planes de Ordenación del Territorio (POT), se organizaba la urbe mediante diferentes figuras de planeamiento y lo rural se dejaba únicamente bajo su propia ordenación agrícola. La nueva problemática de mutaciones requiere una novedosa forma de intervención que puede ser regulada dentro de los POT. Sin embargo, en estos planeamientos el territorio suele encontrarse zonificado en forma de manchas y normalmente todo el territorio suele estar ocupado por usos. De hecho estos planeamientos suelen 
4. Plano de París de 1957. Plano producido por Guy Ernest Debord junto con el pintor Asger J orn. Este plano formaba parte de la obra de Jorn: Pour la forme. Fuente: Andreotti,

L. y Costa, X. Situacionistas: Arte, política, Urbanismo. Barcelona: MACBA, 1997

5. Maqueta del proyecto. Imagen: J avier Romero

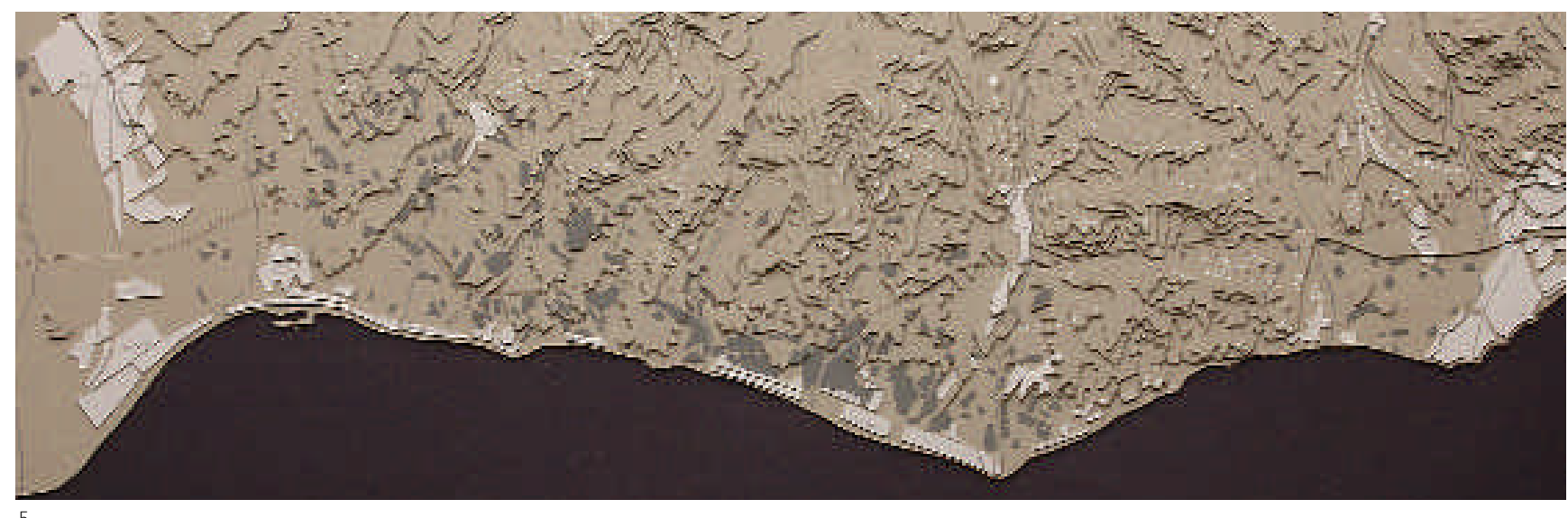

llevar incorporados un plano de usos donde se asigna a una zona de miles de hectáreas un uso específico.

Las propuestas territoriales tradicionalmente proponen una situación definitiva, donde se predefinen usos y actividades concretas para un lugar del territorio. Esto podría ser mejorado. Por ejemplo, el planeamiento incluye el "tiempo" cuando habla de ejecución, faseado o sanción; pero cuando ordena, lo hace buscando algo con una imagen definitiva, una temporalidad infinita. Sin embargo, los sistemas constructivos actuales han hecho que el periodo de construcción de los edificios se haya minorado notablemente, y la durabilidad de sus materiales no perdure mucho en el tiempo, pudiendo encontrarnos que la mayoría de los edificios no durarán en el mejor de los casos más de 25 años intactos, necesitando reparaciones y cambios funcionales constantemente. El planeamiento, sin embargo, ha estudiando con gran profundidad las características de la zonificación, qué usos son compatibles y qué otros no, pero no lo efímero de algunos usos. Esta incidencia respecto a lo temporal de muchos acontecimientos territoriales podría ser incorporada a la planificación como una condición más.

El desarrollo de las poblaciones es necesario y beneficioso, pero no a cualquier precio. Si desarrollar una región implica perder un ecosistema equilibrado, el propio crecimiento se hundirá a largo plazo. El planeamiento debe, por tanto, recoger los funcionamientos territoriales estudiándolos a corto, medio y largo plazo. Por ello no se trataría de estudiar los agentes transformadores del paisaje como elementos negativos sino como nuevas formas de crecer que hay que regular para garantizar su simbiosis con el paisaje y conseguir en equilibrio su perdurabilidad.

\section{El proyecto de paisaje}

El paisaje se puede proyectar, pero no se puede zonificar ni sectorizar, sólo estructurar mediante una buena estrategia. La estrategia queda definida según el diccionario como técnica y conjunto de acti- vidades destinadas a conseguir un objetivo. Si nos desplazamos al campo de la matemática se entiende como un conjunto de reglas que aseguran una decisión óptima en cada momento. Pues bien, efectivamente en el territorio no podemos ceñirnos al ámbito concreto y preciso, trabajamos con la incertidumbre de lo efímero y difuso, sin embargo el hecho de establecer leyes con un objetivo puede generar unas lógicas para un proyecto específico. Esto quiere enunciar que existe una forma de actuar en el paisaje mediante estrategias (materiales e inmateriales), que puede conseguir objetivos comunes e incluso óptimos. Por tanto, al actuar en el paisaje no procederíamos abarcando todo el territorio, ni siquiera desde el estudio pormenorizado de la información que contiene cada metro cuadrado del mismo. Se comenzaría partiendo de actuaciones estructurantes (leyes de actuación) para conseguir un conjunto organizado.

Lo muchas veces inabarcable del territorio dada su extensión y escala hace que las intervenciones no deban incluir a todo el lugar completo sino hacer intervenciones parciales pero estructurantes. Lo que el arte contemporáneo ya avanzaba, la instalación ${ }^{9}$, es hoy la dinámica que hace que se entienda el patrimonio y el paisaje: centros de interpretación, salas temporales en los museos... La aportación de la acción a un lugar es la que lo transforma en llamada de atención para el espectador. Las instalaciones se convierten en nuestro reclamo más cotidiano para que visitemos museos y ciudades. Los espacios cobran vida si se actúa en ellos. La inmersión en un espacio natural por parte de un agente artificial hace que ese espacio sea vivido y disfrutado de otra forma, el juego de la instalación hace que un espacio pueda ser cualquier cosa que se quiera que sea.

\section{Relación entre Patrimonio y Paisaje}

Los campos del paisaje y el patrimonio se encuentran situados en la actualidad en dos ámbitos diferenciados, donde uno necesita del otro para no extinguirse. El paisaje necesita del patrimonio para poder orde- 


\section{Criterios}

Patrimonio y paisaje. Proyecto en el litoral malagueño

Esther López Martín

narse, conservarse, restaurarse e incluso modificarse y el patrimonio necesita del paisaje para encontrarse estructurado en el territorio. Entre los primeros estudios contemporáneos sobre la relación Patrimonio y Arquitectura, ya expresados de forma escrita en el Cuaderno IV del IAPH, se reflexiona sobre los aspectos temporales y su relación histórica con el Patrimonio. Los diversos autores coinciden en lo instantáneo, en el presente como verdadero observador del Patrimonio, en un observador que se posiciona ante el pasado como el "Angelus Novus" ${ }^{10}$ de P. Klee. Confían en una arquitectura que arroja luces y sombras sobre el pasado, pero siempre desde el presente. Con esta reflexión se garantiza una relación tiempo-patrimonio que la vincula a nuestro presente.

El concepto del tiempo se encuentra igualmente expuesto en las cuestiones del paisaje, al depender éste del observador (individualmente) y del momento en el que lo mire (circunstancias climatológicas, personales, percepciones). Es igualmente un tiempo instantáneo que sólo es definido cuando es observado. Es decir, el estudio del paisaje siempre va vinculado al aspecto temporal y al individual, de manera que en él se introduce el tema de la percepción o mirada que claramente están vinculadas al observador.

Patrimonio y Paisaje son por tanto disfrutados desde una instantaneidad en la que el pasado se proyecta desde el presente y los lugares se proyectan sobre los observadores, todo ello a través del instante en que son vividos.

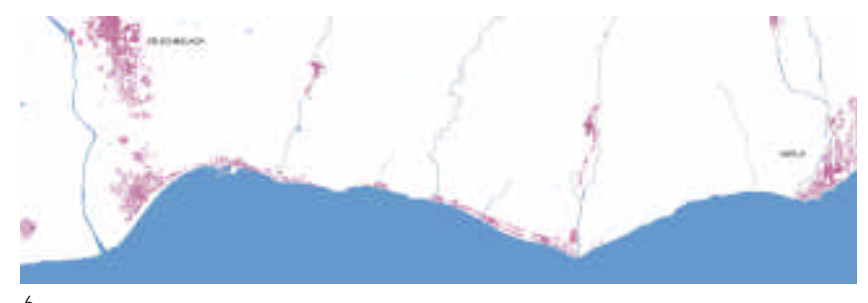

6

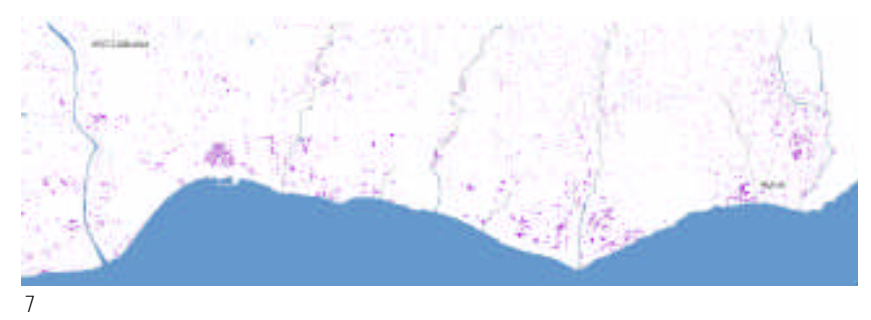

7

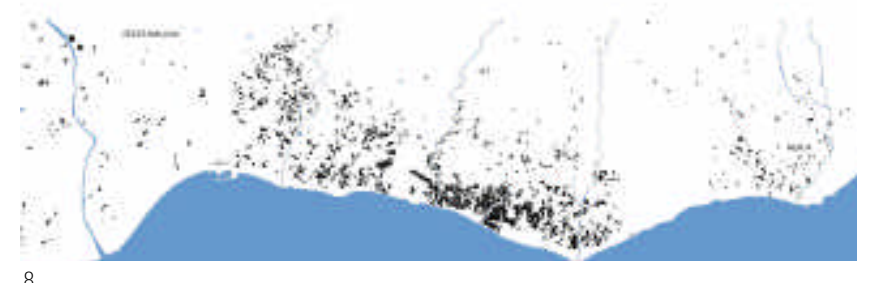

6, 7 y 8. Núcleos urbanos, construcciones diseminadas y cultivos bajo plástico en 1998 9. Panorámica de plásticos y construcciones

10. Imagen de traseras de las construcciones
Según lo anterior, la circunstancia del tiempo condiciona a la percepción, de ahí que se discuta repetidamente entre los profesionales de la geografía la relación entre la subjetividad del paisaje y éste. Efectivamente este factor lo convierte en algo vulnerable y frágil pero valioso igualmente, ya que el paisajista deberá trabajar con elementos como subjetividad, percepción, memoria, creatividad... El paisaje se convierte entonces en otros campos diferentes al de la geografía, como por ejemplo el arquitectónico, en algo muy familiar; esta circunstancia de lo incontrolable y variable es la base de lo que se viene llamando Proceso de Proyecto Arquitectónico, lugar en el que se trabaja de una forma no lineal e inacabada con un hecho concreto (la arquitectura) y donde intervienen multitud de factores que trabajan en él. Es decir, cuando se habla de que lo subjetivo y personal de la percepción convierten al paisaje en un factor incontrolable desde las administraciones por órganos superiores (Planes de Ordenación del Territorio), no es más que un problema semejante al que revolucionó al urbanismo en los últimos años, lo controlable ya no es la forma, es el proceso. El urbanismo no debe decidir la volumetría de los edificios, no puede pensar la ciudad acabada, ni escoger una estética preconcebida para las ciudades, ya que éstas tienen unas lógicas más complejas que "desestructuran" esa ciudad ideal y terminada. Esta disciplina sí tiene que dar las pautas y ordenanzas para que la ciudad crezca con equilibrio, equipada, funcional y abierta, pero no estéticamente predefinida. Es esta forma de proceder la que hace que el urbanismo pase de buscar un fin definido donde se conoce la futura imagen de la ciudad a convertirse en un proceso donde lo que se conoce es la nueva estructura del territorio y qué leyes lo rigen para ser un entorno sostenible, ecológico, con un paisaje que los ciudadanos sientan reconocible y con el que se identifiquen. Es decir, con el aspecto del paisaje nos movemos no en un proyecto convencional, sino en un proceso en el que intervienen factores como la creación, la innovación y el arte.

El estudio del paisaje debería materializarse en un Proyecto de Paisaje. Ésta no es una nueva figura ni algo muy novedoso, es perfectamente abarcable desde los Planes de Ordenación del Territorio y además ya está intuido en ellos. Estos planes incluyen documentación de paisaje; sin embargo, el problema estriba en que se recoge información y no un proyecto de paisaje. Sí se incluyen pequeñas intervenciones como creación de miradores, reestructuración de antiguas canteras..., pero no un proyecto paisajístico integral. El buen hacer de este proyecto de paisaje se conseguiría utilizando como base lo que le viene dado del patrimonio, poniendo en valor la identidad de los lugares.

\section{Percepción. Libro de viaje. Teoría de la Deriva}

Para explicar un poco la propuesta de aplicación de la Teoría en el Territorio de Torre del Mar a Nerja, que más adelante se desarrolla a 


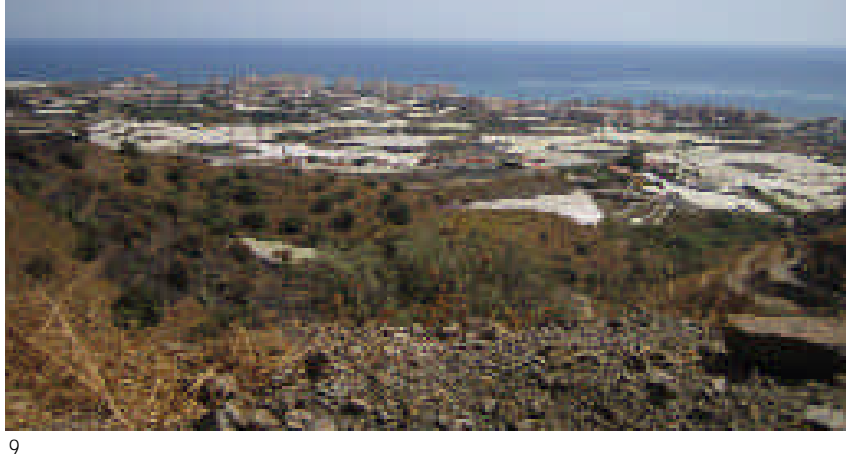

nivel práctico, debemos remontarnos en la historia a mediados del siglo XX, al periodo comprendido entre los años 1957 y 1972, en París. Este periodo temporal era el que abarcaba el inicio y fin de la Internacional Situacionista, que fue la agrupación que enunció y practicó la Teoría de la Deriva. Esta institución cultural la constituían artistas y escritores vanguardistas del momento, que proponían una fuerte crítica a la sociedad consumista de la época y al urbanismo con base en las ideas del movimiento moderno. Opinaban sobre la ciudad y la sociedad basándose en parámetros diferentes, tales como cuestionar que las ciudades deban pensarse desde su utilidad o que se pretendan hacer ciudades modernas y no ciudades para ciudadanos. Vivieron el momento histórico en el que el ser humano quería ser moderno, vivir en casas nuevas, en la ciudad, con confort, bienestar y comodidades aportadas por las nuevas tecnologías de la época y sin embargo este grupo se opuso radicalmente a su tiempo, pretendiendo poner en crisis estas ideas. Se oponían a la dependencia de necesidades recientes, creando una fuerte oposición teórica y práctica hacia la forma de vida moderna.

Para los situacionistas (miembros de la Internacional Situacionista ${ }^{11}$ ), los modelos urbanos anteriores basados en ideas del movimiento moderno, tales como funcionalidad, los avances tecnológicos y la cultura del bienestar no eran más que un engaño teórico imposible e incompatible con el hombre por muchos motivos, ya que entendían que la ciudad no sólo debía pensarse para desplazarse del lugar de residencia al lugar de trabajo sino que debía pensarse como un espacio donde desarrollar lo lúdico y no sólo lo funcional, un espacio para perderse sin prisas ni recorridos prefijados. Realizaron fuertes críticas a la escuela de la Bauhaus, por su carácter teórico así como a importantes arquitectos de la época como Le Corbusier, al igual que en urbanismo a los conceptos expresados en la Carta de Atenas ${ }^{12}$. Planteaban que lo moderno era un sistema de esclavitud de la persona respecto a su tiempo, respecto a lo novedoso e instantáneo. Consideraban que las ideas del movimiento moderno, planteadas desde una absoluta teoría, carecían de realidad y de práctica, eran pensamientos irrealizables. Por lo anterior, proponían una teoría de aplicación llamada "Teoría de la Deriva" donde se practicaba una forma libre, desorientada y no premeditada de recorrer la ciudad, que algunos de sus miembros pusieron en práctica en contadas ocasiones por la ciudad de París.

J unto con el concepto de la deriva, produjeron también otro: la psicogeografía, consistente en los efectos que el entorno geográfico, organizado o no conscientemente, produce en las emociones y el comportamiento de los individuos. Esto queda reflejado en el plano de París, siendo un agente dentro del proceso de lectura del territorio que proponían (imagen 4).

Los situacionistas entendían que el funcionalismo en la ciudad no era real, ya que con esta metodología la ciudad se pensaba con criterios basados en el correcto funcionamiento entre lugares, y optimizando las distancias entre zonas monofuncionales, por ejemplo,

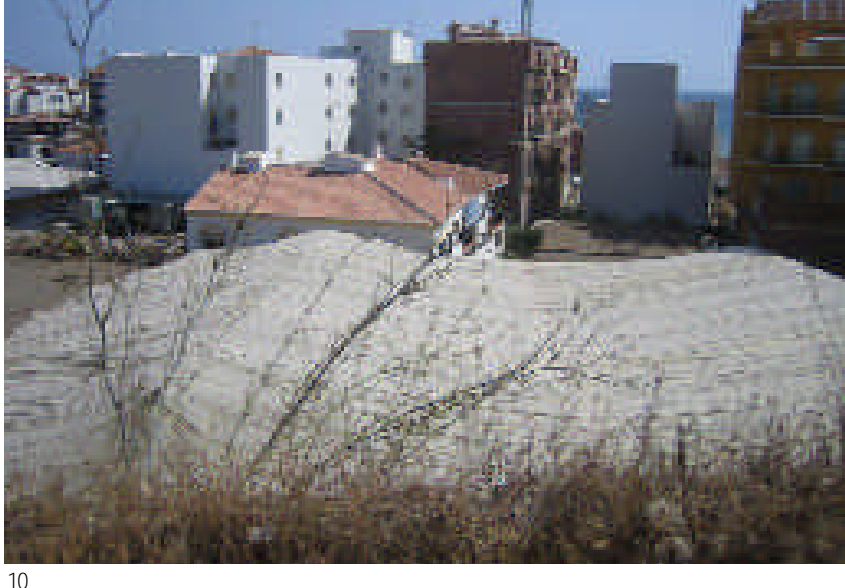

la distancia colegios-residencia o trabajo-residencia. La Internacional Situacionista proponía que lo importante no era el origen y destino, sino el recorrido para llegar de uno a otro, entendiendo que había otras posibilidades de vivir en la ciudad no basadas en una vida rutinaria, mediante otros medios de transporte y otras formas de recorrido tales como el deambular, perderse, recorrer... Otra de las ideas que enunciaban era la negación de que el hombre fuese la escala de referencia para la medida de las cosas, hecho tan enunciado por el movimiento moderno y por Le Corbusier. Ellos aplicaban a la ciudad diferentes escalas de referencia, distintas a la humana.

El concepto de bienestar también fue objeto de reflexión por este grupo de pensamiento, ya que para el movimiento moderno las tecnologías del momento tales como la lavadora, el coche privado, etc. convertían a la sociedad moderna en una sociedad de bienestar siendo el objetivo del ciudadano alcanzar esa condición: el estado de bienestar. Sin embargo, para un situacionista estas necesidades no eran tales; no es el hombre quien las necesita sino es la sociedad de consumo la que crea en el ser humano esa necesidad para subsistir. Por tanto, para los situacionistas, los modernos no eran más que unos esclavos de su tiempo a los que se les creaban necesidades innecesarias para que la sociedad pudiese seguir creciendo económicamente y haciéndose más fuerte.

El urbanismo del movimiento moderno pretendía generar un orden jerarquizado y estructurado para hacer ciudad, mientras que los situacionistas partían del caos existente para reconocerlo y poder trabajar con él. Si analizamos la ciudad contemporánea veremos que la realidad nos demuestra que el urbanismo pensado en la zonificación del movimiento moderno no resuelve problemas hoy en día, por ser muchos los factores que van haciendo cambiar ese zonning. La realidad existente pesa mucho más que los conceptos con los que fueron pensadas las ciudades.

Volvemos a dar un salto en el tiempo y el espacio, pasando de los años cincuenta de París a 1996, en Barcelona. Se inaugura una exposición en el Museo de Arte Contemporáneo de Barcelona (MACBA), en el periodo comprendido entre el 13 de noviembre y el 6 de enero de 1997, llamada "situacionistas"13. Con esta exposición se revivieron los conceptos de la época pudiendo comprobarse posteriormente que eran perfectamente aplicables a la problemática contemporánea. Esta iniciativa fue base de posteriores intervenciones en el ámbito arquitectónico, abriendo una forma de trabajo que se había paralizado años antes y que hoy podía incluso enriquecerse debido a las nuevas tecnologías.

Pocos años más tarde, desde el grupo Rizoma ${ }^{14}$, se vuelve a recuperar el concepto de territorio abarcable desde las propuestas de los situacionistas, anteriormente referenciados. Han sido y son actualmente distintas universidades andaluzas las que han practicado la exploración del territorio mediante una aplicación de la teoría de la 


\section{Criterios \\ Patrimonio y paisaje. Proyecto en el litoral malagueño \\ Esther López Martín}

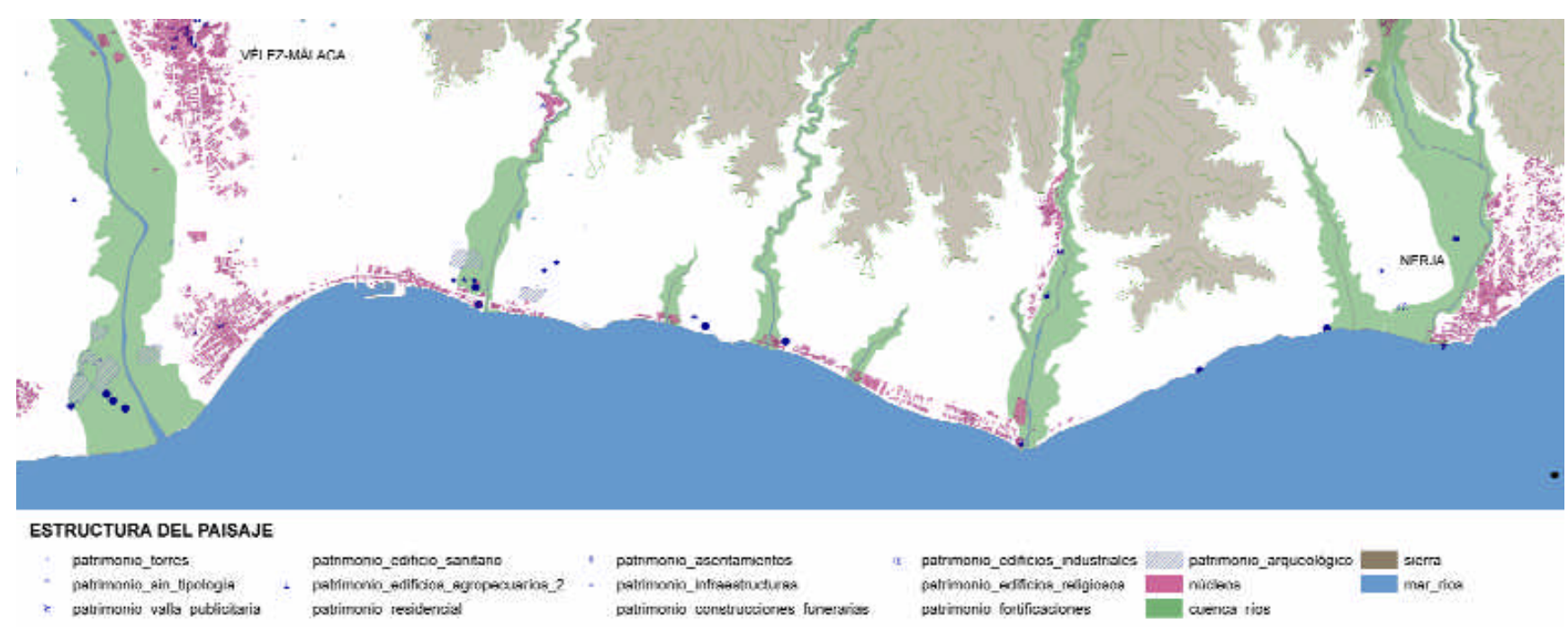

11

Deriva, en colaboración con Rizoma, impartiendo a nivel teórico y práctico la citada situación.

Recientemente, la Escuela de Arquitectura de Granada ha experimentado una deriva masiva en las costas de Málaga, concretamente en el territorio que se define como ZoMeCS (Zona Metropolitana de la Costa del Soll) ${ }^{15}$. Este grupo de trabajo planteaba la deriva masiva como una nueva lectura territorial donde se actuaba desde el deambular definido por los situacionistas. También incorporaba la necesidad de reflejar en esa deriva masiva las nuevas tecnologías y posibles lecturas, así como el carácter liso 0 estriado $0^{16}$ de los espacios que el alumnado iba apreciando en su deambular por la costa. Este recorrido culminó en una publicación que narra la experiencia de la deriva recogiendo todas las impresiones, sin una selección previa de las mismas.

\section{Aplicación de la metodología}

A continuación se inicia una aplicación práctica basada en todo el desarrollo teórico anterior. Se propone una forma novedosa de actuar en paisaje, la aplicación de diferentes lecturas del mismo:

1. Ejecución de maqueta del lugar

2. Evolución histórica

3. Deriva no urbana

4. Evolución a lo largo del año

5. Estructura del paisaje

6. Proyecto de paisaje

Esta aplicación se ha desarrollado en un sector del litoral andaluz donde conviven formas mutantes de crecimiento contemporáneo, en concreto: construcciones destinadas al turismo y cultivo bajo plástico. Se trata del arco comprendido entre Torre del Mar y Nerja (Málaga), donde estos crecimientos son relativamente recientes, pero de un enorme potencial. En esta zona de Andalucía plástico y turistas conviven en vecindad.

\section{Evolución histórica}

El territorio de estudio que comprende los municipios actuales de Vélez-Málaga, Algarrobo, Torrox y Nerja, ha sido ocupado desde la antigüedad. Son numerosos los yacimientos que nos dan información sobre ello: Toscanos, Trayamar, Cerro del Mar, Chorreras... En esta época la ocupación territorial se dispersaba cercana a la costa por motivos estratégicos para el comercio.

Es en la Edad Media, en la época musulmana, cuando se ocupa el sector de una forma diferente, bajo criterios principalmente de estrategia militar, constituyéndose el origen de los actuales núcleos de población, tales como Vélez-Málaga, Nerja... Igualmente, surgieron alquerías (núcleos rurales) vinculadas a la ciudad fortificada de Vélez-Málaga que hoy se identifican como núcleos urbanos (Almayate, Iznate, Cajiz...). Fue también la época en la que se construyeron algunas de las torres vigías tan reconocibles hoy desde el paisaje y que se prolongan por todo el litoral. Tan sólo en la franja litoral objeto de estudio, de $20 \mathrm{~km}$, tenemos 10 torres vigía documentadas.

Tras la expulsión de los musulmanes en el S. XV, los mudéjares huyen hacia las alquerías. Igual que en los restantes pueblos de la Axarquía, la zona sufrió las consecuencias de la rebelión de los moriscos, la expulsión de éstos y las siguientes repoblaciones, así como los efectos de la epidemia de fiebre amarilla que azotó 


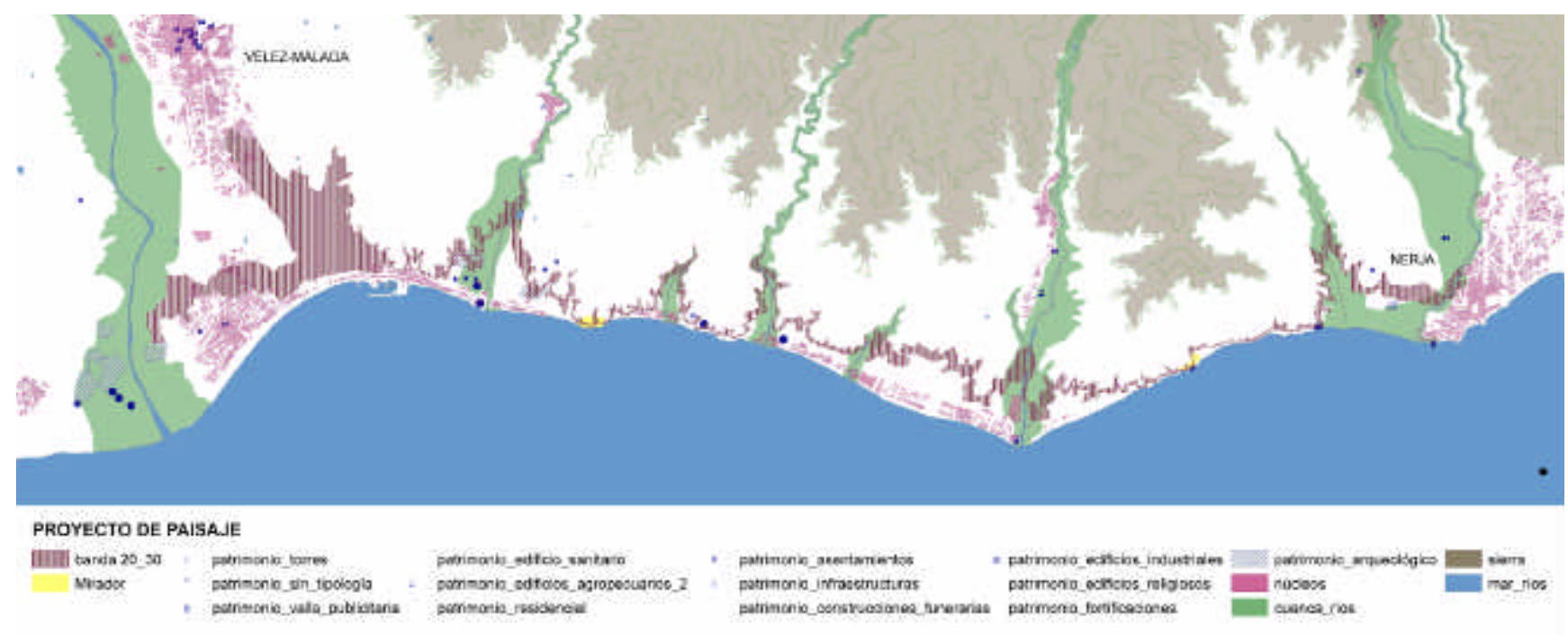

12

Málaga a principios del s. XIX y los estragos de la invasión napole ónica. Fue el cultivo de la caña de azúcar lo que hizo no hundirse a gran parte del sector, de forma que se construyeron varias fábricas destinadas a su explotación.

En el siglo XX, vuelve a darse un cambio económico en la zona, iniciándose la creación de balnearios como reclamo para un turismo incipiente. Ya en los años cincuenta, se observa ${ }^{17}$ cómo el sector de Vélez-Málaga a Nerja estaba constituido por pequeños núcleos urbanos, unos de litoral y otros de interior dispersos, y un importante desarrollo agrícola en torno a los ríos Vélez, Torrox, Algarrobo y Seco.

A finales del s. $X X^{18}$ el cambio territorial es espectacular, multiplicándose enormemente la superficie ocupada por edificación en los núcleos de población existentes y creándose un curioso fenómeno donde se producía duplicidad de núcleos de población dentro de un mismo término municipal. Es decir, a los pueblos interiores les surgía un arrabal costero destinado exclusivamente a fines turísticos y que con el paso de los años acaba por tener mucha más población que el núcleo del que depende administrativamente, como ejemplos los casos de Algarrobo-Algarrobo Costa, TorroxTorrox Costa, Almayate Alto-Almayate Bajo, etc. Acompañando a este crecimiento binuclear, se generó un proceso de crecimiento disperso por la totalidad del territorio llegando a crear un tapiz de pequeñas construcciones que ocupan todo el terreno entre ciudades. A este crecimiento le acompaña un cambio en los sistemas de producción agrícola en los que se practica el cultivo intensivo bajo invernadero, disponiéndose plásticos en los valles de los ríos principales del lugar. Los gráficos 6, 7 y 8 segregan por capas estas tres formas de ocupación territorial: núcleos urbanos, construcciones diseminadas y cultivos bajo plástico.

\section{Deriva no urbana}

Buscando una mirada diferente del paisaje, que aporte nuevas lecturas territoriales, se ha procedido a realizar una deriva en la zona de estudio. Ha sido una deriva individual que ha supuesto dos días de trabajo de campo y se ha centrado en la zona no urbana del sector de estudio. Difiere por tanto de las originales derivas realizadas por la Internacional Situacionista en París debido a su carácter fuera de la ciudad.

Nada más llegar, se observa que la orografía es muy abrupta, existiendo infinitos desniveles en todo el arco litoral. Debido a esto los caminos son zigzagueantes y de gran longitud por lo que la deriva se realiza en coche.

El deambular ha sido un ir y venir de la sierra al mar, y se han conseguido multitud de informaciones parciales que sumadas nos dan una visión personal pero interesante respecto a la globalidad de la zona de estudio.

El recorrido inicial nos desvela un territorio invadido por los plásticos y las construcciones donde se aprecian importantes cambios entre los diferentes lugares. J unto a las zonas turísticas tenemos un amplio territorio destinado a la agricultura e industria. Estos lugares no se enseñan al turista pero están junto a sus viviendas.

Deambulando y dispersas por el territorio, se descubren varias industrias abandonadas, procedentes en su mayoría del cultivo de caña de azúcar tan explotado antaño y que hoy es inexistente. La que está en Torre del Mar, junto a la vivienda Larios, se encuentra en proceso de rehabilitación; las restantes se encuentran abandonadas.

J unto al mar, hay elementos que sirven de referentes paisajísticos, como son las torres vigía, aún hoy visibles, pero a las que se augura 


\section{Criterios}

Patrimonio y paisaje.

Proyecto en el litoral

malagueño

Esther López Martín

un futuro incierto debido a que se están desarrollando en la zona actuaciones urbanísticas donde los aspectos como el paisaje, el medioambiente, la ecología, el patrimonio... no se tienen en absoluto en cuenta (imagen 9).

En general, una deriva por el territorio nos descubre un paisaje frágil y cambiante. Esta zona costera se presenta como un conglomerado de industrias y cultivos de difícil acceso y sin ninguna urbanidad. La mayoría de los caminos se encuentran sin asfaltar y muchos no tie nen salida ni conexión con otros lugares. La zona urbana desde estos terrenos se ve como multitud de traseras de edificios sin fachada que todos ellos parecen dar la espalda a la montaña por encontrarse mirando al mar (imagen 10).

No obstante la problemática anterior, el colapso no ha llegado aún y el territorio costero es aún un lugar de oportunidad para intervenciones en el paisaje. El territorio estudiado es complejo y variado, reuniendo todas las características de los crecimientos contemporáneos, por ello un tratamiento paisajístico del conjunto podría ser la solución al futuro incierto que se le augura a medio plazo.

\section{Evolución a lo largo del año}

El estudio del comportamiento del sector a lo largo del año nos revela mucha información sobre la forma de vida en él. La franja comprendida entre el mar y la autovía se encuentra ocupada por la población más eventual y veraniega, existiendo importantes diferencias entre el verano y el resto del año: viviendas deshabitadas, locales con apertura exclusivamente veraniega... Es el área que peor funciona a lo largo del año, ya que o está colapsada o deshabitada. La zona que se encuentra al norte de la autovía, sí tiene un funcionamiento más homogéneo a lo largo del año; no obstante, tiene la grave problemática de las construcciones diseminadas.

Se obsenva también un mal funcionamiento de las vías de comunicación a nivel local, ya que se usa la carretera nacional para distancias muy cortas dentro de cada núcleo de población como si se tratase de una vía urbana, y la autovía se usa para comunicaciones dentro de la provincia.

\section{Estructura del paisaje}

Existe un importante patrimonio arqueológico y arquitectónico en la zona, no obstante ha sufrido gravemente las consecuencias de la expansión urbanístico-turística, tal es el caso de las torres vigías. De las diez existentes, se conservan 2 a nivel arqueológico, 2 inmersas dentro de la trama urbana y tan sólo las 6 restantes conservan una importante presencia arquitectónica en el paisaje.

La riqueza patrimonial de la zona es abundante y variada, existiendo desde preexistencias arqueológicas de la protohistoria a edificios industriales del siglo XX e incluso consta un importante patrimonio subacuático (Pecio de la Mezquitilla). También destaca el patrimonio natural de la sierra, junto con el de los valles de los ríos y el mar. Si unidos al patrimonio documentado conseguimos objetivar los elementos identificativos de un lugar, tendremos caracterizada la estructura del paisaje (imagen 12). Ésta será la base de la futura intervención.

La estructura del paisaje nos desvela que los elementos que lo conforman (sierra, valle-ríos, núcleos estructurantes y patrimonio concreto documentado) se encuentran conectados de una forma natural en sentido transversal, es decir, de la montaña hacia el mar, pero sin embargo hay una total desconexión longitudinal entre ellos debido a la naturaleza geográfica del lugar y a que las vías de comunicación en esta dirección son todas ellas vías rápidas, carentes de la posibilidad de pasear, deambular... Este es el motivo por el cual, ante el peatón, el paisaje aparece confuso y, a excepción del mar, estos elementos no se perciben con claridad. El conjunto se presenta como un importante escaparate turístico que oculta otras posibilidades culturales y paisajísticas de valor.

\section{Proyecto de paisaje}

Tras las distintas lecturas propuestas y la definición de la estructura del paisaje, se ha pretendido realizar un proyecto que ponga en valor las relaciones entre Paisaje y Patrimonio y que invite al peatón a descubrir el paisaje de su entorno más inmediato. Para ello se han definido tres tipos de áreas paisajísticas: estructura del paisaje, banda estructurante y paisaje no estructurante. La estructura del paisaje es el conjunto de elementos que definen e identifican a un lugar, son la expresión gráfica de los valores patrimoniales del lugar. La banda estructurante es el eje vertebral del territorio, un espacio artificial que intenta poner en valor todo el patrimonio que lo rodea. El paisaje no estructurante es, por eliminación, todo lo que no es lo demás.

Analizando las curvas de nivel de la zona de estudio, se observa que tanto la entrada a Nerja como el sureste de Vélez-Málaga se encuentran a $30 \mathrm{~m}$ sobre el nivel del mar. Exactamente a la misma cota. Por lo tanto esta altitud nos permite conectar a una cota constante los núcleos de población más importantes del sector. Si a esto unimos que, al ser los núcleos más distantes existentes, la unión entre ellos implica un recorrido por todo el territorio, tenemos un potencial paisajístico muy importante. Por ello, se propone crear una banda paisajística que no es más que el ámbito comprendido entre los 20 y los $30 \mathrm{~m}$ de altitud que recorre el territorio.

Al ser un elemento que pasa por todos los valles de los ríos, es a su vez el camino que permite llegar a la sierra desde el mar. El recorrido permite la visualización del mar y a su vez deja descubrir todo el patrimonio, incluso las torres vigías existentes y la relación visual entre ellas. Esta banda de recorrido va variando su ancho tal y como se aprecia en la planimetría, en función de las características geográficas, oscilando entre $10 \mathrm{~m}$ y más de un kilómetro de ancho. Territorialmente se compondría de elementos diferentes: un paseo 
13. a. Torrecilla de Nerja; b. Torre de Macaca; c. Torre de Calaceite; $d$. Torre de Gui; e Torre de Lagos; f. Torre Derecha; g. Torre Ladeada; $h$. Torre Manganeta

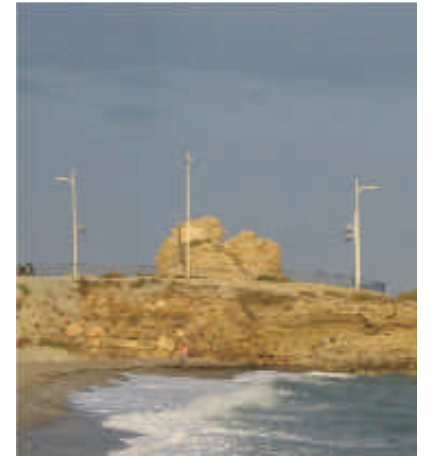

13. a

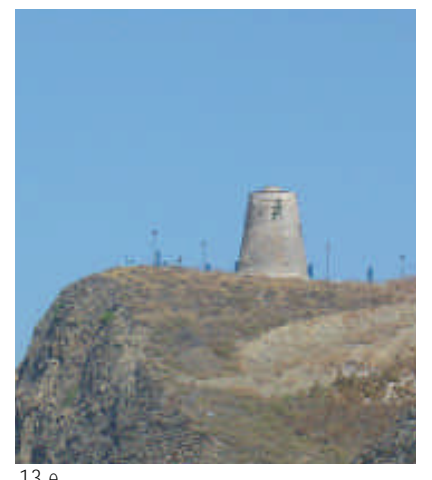

13.e

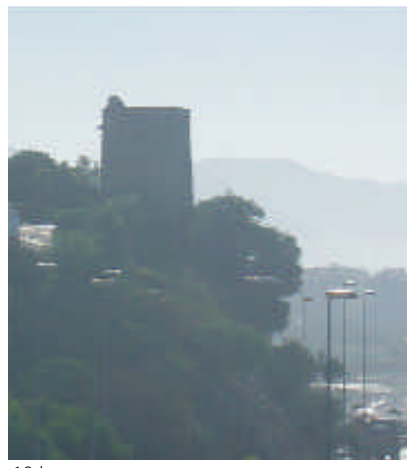

13.b

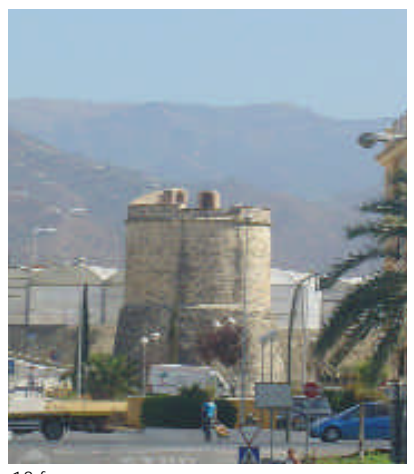

$13 . f$

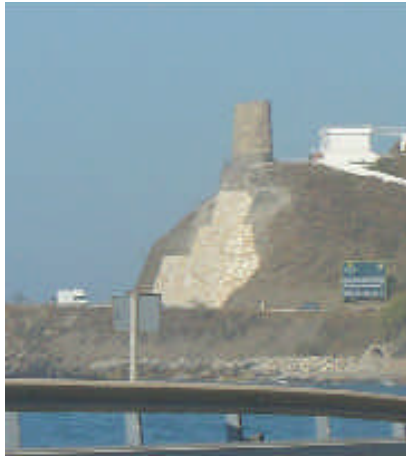

13.c

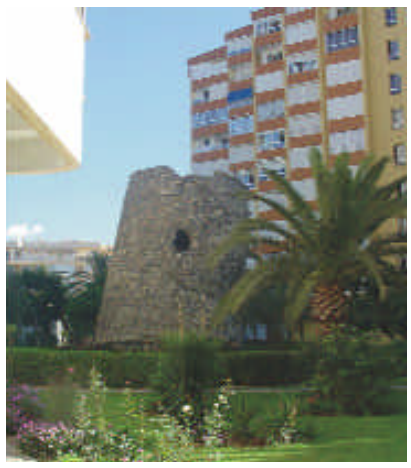

13.9

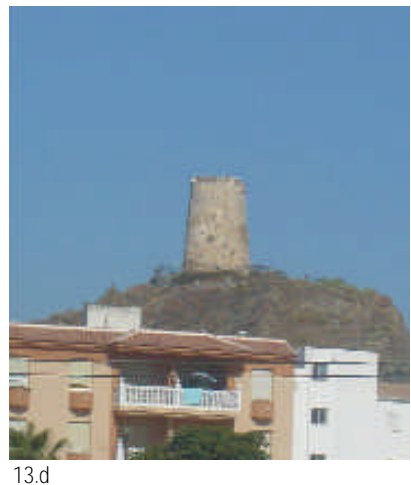

13.

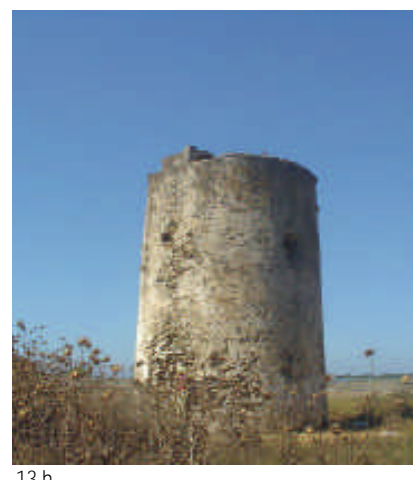

13.h

peatonal con áreas de estancia y descanso, un carril para bicicletas, un oasis verde de árboles autóctonos y, en otros, un simple camino... obteniendo un recorrido muy libre donde las distancias a recorrer pueden ser parciales y totales, y que conecta los distintos núcleos de población así como resuelve las relaciones internas dentro del núcleo. El objetivo sería ofrecer a los residentes la posibilidad de ir a trabajar o estudiar por un recorrido paisajístico. Al ser una cota constante, tendrá una característica muy favorable, que sería su excelente accesibilidad. Se ha de indicar que esta banda paisajística podría tener continuidad tanto hacia el este como hacia el oeste; no obstante el estudio de su viabilidad sería objeto de otros proyectos paisajísticos, y en este caso nos ceñiremos a este sector en concreto.

Se han señalado dos puntos estratégicos que deberían ser desarrollados al igual que la banda paisajística a una escala mayor, ya que el presente estudio del paisaje se ha centrado en la escala territorial y siempre se han concretado las actuaciones a la definición necesaria a $1: 30.000$.

Para garantizar el funcionamiento de una futura intervención, los proyectos parciales sobre la banda estructurante deberían seguir fielmente el funcionamiento global del sector y nunca concebirse como parques públicos locales sino como conectores paisajísticos entre localidades y en definitiva entre paisajes. La propuesta implica un funcionamiento global e intermunicipal de la zona.

El proyecto planteado genera incompatibilidades con los terrenos explotados mediante la agricultura intensiva. Por ello, dicha explotación no debería ubicarse ni en las zonas denominadas estructura del paisaje ni en la denominada banda paisajística. Debiendo desaparecer esta forma de cultivo de estas zonas: valles de los ríos, sierra y banda paisajística, y pudiendo sustituirse en estos lugares por explotaciones con árboles y arbustos autóctonos. Para las áreas no estructurantes sí serían compatibles; no obstante, dado el problema paisajístico que genera esta forma de cultivo, deberían estar sujetos a un proyecto concreto de paisaje. Para ello habría que, junto con los afectados y técnicos, plantear una alternancia de cultivo, que permita la desaparición del plástico en algunas épocas del año permitiendo la oxigenación del suelo y una presencia paisajística más acorde con el uso predominante: turismo. Por tanto serían admisibles estos cultivos sólo si son eventuales.

El sector se compone de dos arcos: De Torre del Mar a Torrox Costa y de Torrox Costa a Nerja. El primero de ellos, debido al crecimiento urbanístico, ha perdido un valor irrecuperable que es la posibilidad de mantener la visual entre las torres vigías existentes, debido a que las torres Ladeada y Derecha se han quedado dentro de la ciudad. Sin embargo, con la banda paisajística se recupera un lugar estratégico, donde se recomienda la instalación de un punto informativo y a la vez mirador; en él se podría incluso informar al paseante sobre el valioso patrimonio sumergi- 


\section{Criterios}

Patrimonio y paisaje. Proyecto en el litoral malagueño

\section{Esther López Martín}

do de la zona y sobre el resto de lugares de interés, incluido el yacimiento arqueológico de chorreras donde se instalaría este mirador. En el segundo arco hacia el mar, al mantenerse las visuales entre las torres, la propia historia nos enseña el paisaje que se convierte en esta zona en un paseo por el tiempo.

Con el proyecto de paisaje, estos dos arcos serían registrados por la banda de paisaje propuesta, creando un hilo conductor de lugares de interés patrimonial. Se ha puesto en valor lo que lo convierte en identificativo y valioso, dejando descubrir a quien lo recorra toda la riqueza de su patrimonio.

\section{Notas}

${ }^{1}$ Autor del libro Proyectar con la Naturaleza, publicado en 1969. Tal y como se indica en la introducción a la edición española de este libro: "El método de McHarg facilitó el desarrollo de los Sistemas de Información Geográfica (SIG), sobre todo gracias a un grupo de investigadores de Harvard que, motivados por las conferencias de los años sesenta, desarrollaron los primeros soft ware. Así, Jack Dangermond, presidente y fundador de ESRI (Enviromental Systems Research Institute), en Redlands, California, autores de ArcInfo y Arcview, entre otros, afirmaba que el profesor McHarg había creado el contexto en el que el SIG pudiera florecer".

2 El autor del libro ¿De qué tiempo es este lugar?, Kevin Lynch, ya enunciaba en 1972 un concepto semejante donde dice: "Es posible diseñar para una iluminación artificial tanto como para la luz solar, para que estén llenos o vacíos, para que ofrezcan un aspecto ruinoso o fresco y renovado. Otras hazañas de este mismo género resultan más difíciles, por ejemplo, crear un auditorium que sea distintivo y satisfactorio cuando esté atestado o casi vacío, 0 un aparcamiento 0 un lugar de acampada que sea hermoso cuando está ocupado o cuando no lo está". (Lynch, K. ¿De qué tiempo es este lugar? Barcelona: G. Gili, 1975, pp. 200-202).

${ }^{3}$ AA.W. (2000) Mutations. Barcelona: Actar, 2000. En este libro, Rem Koolhaas, junto a Harvard Project on the City, Stefano Boeri y otros, hacen una reflexión sobre los procesos de transformación que acontecen en la ciudad contemporánea, donde la flexibilidad de los espacios se hace imprescindible para su crecimiento. Se analizan grandes ciudades como: Lagos, algunas ciudades estadounidenses y el Delta del Río de las Perlas en el Sudeste Asiático.

${ }^{4}$ EI doctor arquitecto Carlos García Vázquez tiene un artículo llamado "Museificación de Territorio", (Neutra. Revista de Arquitectura, no 9-10, 2003, pp. 28-29) donde compara el cuadro de Joan Miró "Campo Cultivado" de 1930 con el de "Blanco sobre fondo blanco" de 1925 de Malevich como dos formas diferentes de actuar en el patrimonio.

${ }^{5}$ La revista Quaderns (no 217, 1997) tiene un monográfico sobre esta tendencia donde el paisaje se "arquitectoniza" produciendo nuevas dinámicas disciplinares situadas a medio camino entre el artificio y la naturaleza.

${ }^{6}$ El grupo de arquitectos paisajistas West 8 (Holanda), dirigido por Adrian Geuze, tiene una instalación en una zona pantanosa de Charleston, Carolina del Sur (USA) 1997, donde tensando cables que se disponen entre los árboles y colgando líquenes de ellos, se accede a un nuevo paisaje verde a través de la ubicación de un nuevo embarcadero. Publicado en Amidon, J ane. Paisajes Radicales. Barcelona: Blume, 2003.

${ }^{7}$ En una pequeña aldea de montaña de la Prefectura de Gifu (J apón) 1992, el paisajista Makoto Sei Watanabe introduce un pabellón en un paisaje montañoso, según explica el mismo Watanabe: "No consistía en dejar la naturaleza como es, sino en extraer más aún su belleza añadiendo pequeños objetos artificiales". Publicado en Amidon, Jane. Paisajes Radicales. Barcelona: Blume, 2003, p.105.
${ }^{8}$ Artículo publicado en el libro Prix Mediterranée du paisaje (Sevilla: J unta de Andalucía, 2001, pp. 24-25). También añade que, por el contrario, hoy en día cada vez más surgen los viajes exóticos, se refuerzan los folklores, surgen nuevos nacionalismos... es decir, en un mismo tiempo, se conjugan dos formas extremas de actuar. Y es que realmente, el miedo a la globalización está provocando la humana necesidad de arraigarse a lo autóctono y local, a una necesidad de encontrar en el entorno nuestra identidad, nuestro patrimonio.

${ }^{9}$ Artículo del arquitecto Manuel Gausa (revista Quaderns, no 217, 1997, pp. 51-53). “El paso de la escultura a la instalación se extrapola hoy a una arquitectura convertida así en presencia disuelta, fundida; transgresora, desenfadada, insólita, definitivamente artificial pero no arrogante; positiva, no impositiva".

${ }^{10}$ En esta publicación se hace mención a una de las tesis (Tesis IX de "Tesis de Filosofía de la Historia") del pensador alemán Walter Benjamin, donde se indica: "Hay un cuadro de Klee que se llama Ängelus Novus. En él, se representa a un ángel que parece estar a punto de alejarse de algo en lo que fija la mirada. Sus ojos están desmesuradamente abiertos, la boca abierta y extendidas las alas. Y éste deberá ser el aspecto del ángel de la Historia. Ha vuelto el rostro hacia el pasado. Donde a nosotros se nos manifiesta una cadena de datos, él ve una catástrofe única que amontona incansablemente ruina sobre ruina, arrojándolas a sus pies. Bien quisiera él detenerse, despertar a los muertos y recomponer lo despedazado. Pero desde el paraíso sopla un huracán que se ha enredado en sus alas y que es tan fuerte que el ángel ya no puede cerrarlas. Este huracán lo empuja irresistiblemente hacia el futuro, al cual da la espalda, mientras que los montones de ruina crecen ante él hacia el cielo. El huracán es lo que nosotros llamamos progreso".

${ }^{11}$ Fundada por Guy-Ernest Debord tras encontrarse varios años unido al movimiento letrista de Isidore Isou. Dio expresión escrita a la fundación mediante la revista Potlatch (1954-1959). En este grupo situacionista también mencionamos a Michele Berstein, Asger Jorn, Constant, T.J. Clark, Raoul Vaneigem, A.F. Conord, Gil J. Wolman, Nicolas Gogol...

${ }^{12}$ Documento aprobado en el CIAM (Congreso Internacional de Arquitectura Moderna) en 1933. Fue redactada por los arquitectos y urbanistas más importantes del momento entre los que destacaba Le Corbusier y supuso un importante hito en la historia del urbanismo y arquitectura de la época. Planteaban una crítica a la ciudad histórica y poco funcional a favor de una ciudad pensada desde sus inicios como racionalista, equilibrada medioambientalmente, higiénica y con garantías de bienestar para el ciudadano.

${ }^{13}$ Unidos a esta exposición, se encuentra su catálogo Situacionistas. Arte, Política, Urbanismo (Andreotti, Liberto y Costa, Xavier. Barcelona: MACBA, 1997) y el libro Teoría de la Deriva y otros textos situacionistas sobre la ciudad (Andreotti, Liberto y Costa, Xavier. Barcelona: Actar y Macba, 1997). Este último contiene una selección de escritos de la Internacional Situacionista.

${ }^{14}$ Rizoma (www.rizoma.org) es una revista sin periodicidad de arquitectura, cuyo primer número se editó el 15/09/94 y donde se plantean diferentes cuestiones y reflexiones sobre la arquitectura y el urbanismo contemporáneo, muchas veces con casos concretos de la ciudad de Málaga, ciudad donde residen sus redactores y creadores. Entre ellos, geógrafos y arquitectos, destacamos a Eduardo Serrano, Alfredo Rubio, José María Romero, Rafael Reinoso...

${ }^{15}$ Existe una publicación de la Deriva Masiva realizada en ZoMeCS, un libro llamado Un Proyecto Colectivo 020404. Deriva en ZoMeCS (Rizoma, 2004).

${ }^{16}$ Referente al libro Mil Mesetas: capitalismo y esquizofrenia (Deleuze, Giles y Guattari, Félix. Valencia: Pre-Textos, 1988). Buscaban una aplicación práctica de los conceptos desarrollados en este libro.

${ }^{17}$ Según vuelo fotogramétrico realizado por el ejército de los Estados Unidos en 1956.

${ }^{18}$ Según vuelo fotogramétrico realizado en 1982 aportado por el Instituto Geográfico Nacional (IGN) y cartografía digital pormenorizada del plano de Andalucía 1:10.000, realizado por el Instituto de Cartografía de Andalucía (ICA). 